\title{
Risk Appetite and Emerging Market Spreads
}

\author{
Martín González-Rozada \\ UTDT \\ and \\ Eduardo Levy Yeyati \\ UTDT and Brookings Institution
}




\title{
Risk Appetite and Emerging Market Spreads ${ }^{1}$
}

\author{
Martín González-Rozada \\ UTDT \\ Eduardo Levy Yeyati \\ UTDT and Brookings Institution
}

June 2010

\footnotetext{
${ }^{1}$ Prepared for Financial Contagion: The Viral Threat to the Wealth of Nations, edited by Robert Kolb, John Wiley \& Sons. The authors would like to thank Cristian Alonso for excellent research assistance. This article is based on our research paper "Global Factors and Emerging Market Spreads" published by The Economic Journal Vol. 118, Issue 533, pp. 1917-1936, November 2008.
} 


\section{Introduction}

Global credit conditions have often been key determinants of the borrowing costs of emerging economies, for good reasons. In principle, the pricing of debt issued by financially integrated emerging economies should be no different from the pricing of noninvestment grade securities in general, and low-grade bonds in developed economies in particular. Both should reflect the level of risk of the security, and a risk premium (the price of risk) that is, in turn, a reflection of the risk appetite of the international investor. In addition, global liquidity influences the international cost of capital and, to the extent that this cost affects debt sustainability, emerging market spreads. Then, an important part of the variability of emerging spreads could be seen as a reflection of exogenous factors (such as the international business cycle, or global liquidity crunches and asset selloffs) that simultaneously determine both risk appetite and the interest rate.

The aftermath of the 2008 global financial crisis is a case in point: the combination of fiscal stimulus packages across the board in 2009 with a disappointing growth performance, sovereign spreads in 2010 has started to reflect growing concerns about the ability of developed economies to service their debt obligations. In this context, improving fundamentals in most emerging economies have been offset by a deteriorating risk appetite, and fears of a devt restructuring in the eurozone have been detrimental to risk assets in general, and non-investment grade credits in particular. At any rate, global factors continue to be a critical input in debt sustainability analysis in the developing world.

In this article, we document in a rigorous and systematic way the degree to which the evolution of emerging market spreads has been determined by exogenous global factors. Specifically, we show how changes in international interest rates and corporate bond spreads in advanced countries explain the dynamic (within) country variability of emerging market spreads in recent years. Indeed, global factors such as risk appetite, global liquidity and contagion from systemic events like the Russian and Mexican debt crises in the 1990s account for the major part of emerging market spread movements. On the other hand, we do not find a significant effect on the pricing of emerging market debt from changes in credit ratings, which appear to lag large spread corrections. The evidence reported here highlights the recent shift in the policy debate from debt sustainability to debt vulnerability, including through the emphasis of liquidity as much as solvency issues, as spread widening episodes are often triggered by external, exogenous factors rather than by country-specific fundamental changes.

\section{Model and data}

We consider a model where spreads depend on the price of credit risk, which in turn depends on the international risk free rate and the risk appetite of international investors, 
the incidence of the default risk of the issuer as a function of its fundamentals, and global factors such as global liquidity or episodes of financial distress that affect corporate and emerging markets differently. We explain the evolution of the spreads using a panel error correction model that describes a basic long-run equilibrium relationship between markets spreads, the price of credit risk and the international rate but at the same time allow us to have a complete characterization of the impact of global factors in the short-run (see Gonzalez-Rozada and Levy Yeyati, 2008 for a detailed description of the model, the statistical properties of the individual variables, and the econometric estimation).

We use Credit Suisse First Boston's High Yield Index (HY), which measures the spread over the US treasuries yield curve at the redemption date with the worst yield as a proxy for the price of risk and,the 10-year US Treasury rate (10YT) as a proxy for international liquidity. We also construct a credit rating variable based on Standard \& Poor's rating for

long-term debt in foreign currency to use mainly as a control for country-specific fundamentals,

Emerging market sovereign spreads are measured as the spread over Treasuries of J. P. Morgan's EMBI_Global Index (EMBI) for each of the 33 emerging economies in the Global portfolio. We work alternatively with monthly, weekly and (occasionally) daily data for the period 1993-2005.

\section{Global factors and spreads.}

At first sight, data appears to support the view that global factors exert a strong influence on emerging market spreads. In Figure ZZZ.1 we present the median of individual EMBI spreads at each point of time, and the distribution around its cross-section mean. We include as well the evolution of our two main proxies of global factors. As can be seen, HY and EMBI have indeed moved together over the last 10 years. Even in the previous period there is a co-movement, but somewhat lower because of the strong impact of contagion from the Mexican and Russian crisis. Moreover, there seems to be also a direct relationship between the emerging market spreads and international liquidity.

A more rigorous analysis confirms this first impression. We estimate the spread as a longrun function of the high yield index, the international interest rate, contagion from crisis abroad (Mexican and Russian ones) and the credit rating. Using monthly data, the correlation is large and highly significant for all the variables. In particular, two exogenous global factors, HY and 10YT, explain about $30 \%$ of the dynamic within variability of spreads, $37 \%$ if we add contagion and close to $60 \%$ if we include credit ratings too. Short run estimates are also consistent. All variables have strong contemporaneous impact on spreads but not delayed effect, and only $7 \%$ of deviations from the long-run level are eliminated per month, so the average lag length is about fourteen months. Same story is 
told when weekly data is considered: high correlation, strong explanatory power and slow convergence.

It is interesting to highlight that sovereign spreads adjust close to one to one to changes in the international interest rate in this baseline specification. This would suggest that the influence of the risk-free rate goes beyond the standard arbitrage view (Calvo et al., 1993) and that borrowing costs in emerging economies respond more than proportionally to the interest rate cycle in the developed world. 
Figure ZZZ.1. EMBI Index, high yield spreads and international rates
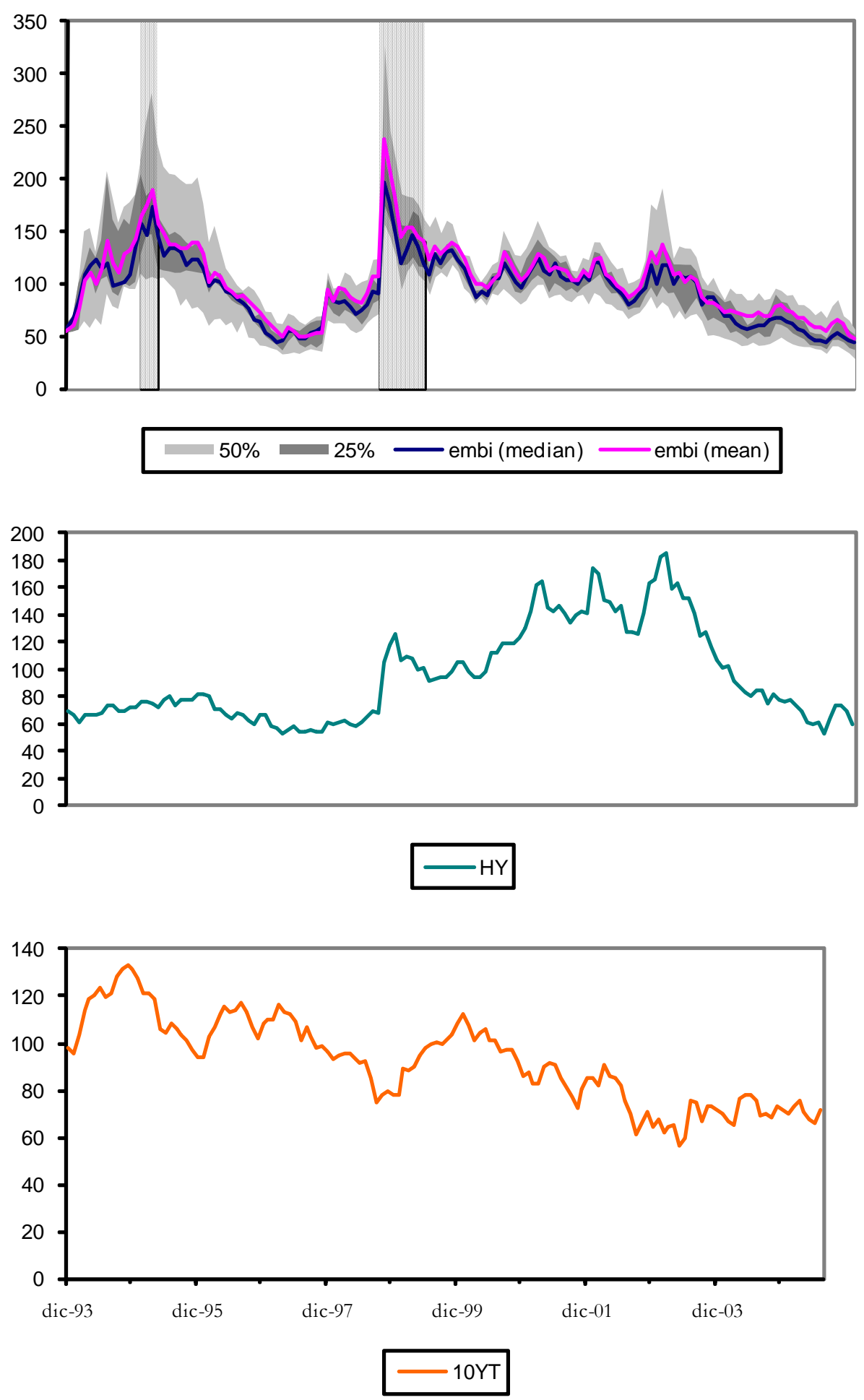


\section{Global factors then and now}

Capital markets have experienced significant changes over the last two decades, especially for emerging economies. Due to the increasing integration of capital markets and to the growing familiarity with the emerging market asset, it would be natural to think that the impact of global factors over spreads has changed. In particular, we would expect this connection to have strengthened over the years.

To check this hypothesis we split the sample into two subsamples, 1993-1999 and 20002005, and we re-estimate our model. We find that the HY coefficients are larger for the earlier period both in the short and long-run equation, while their explanatory power is comparable and even increases for the long-run equation in the later years. However, from an economic perspective, the estimates for the second part of the sample indicate that a $10 \%$ increase in the risk-free rate brings a $7.6 \%$ increase in spreads, whereras the same change in the high-yield spread is reflected almost one to one on emerging market spreads. On the other hand, a one-notch upgrade in ratings is associated with a reduction in spreads of $35 \mathrm{bps}$. These results would indicate that, based on the values of global factors and the emerging market average rating by end-2005 $(\mathrm{BB}+$, roughly equal to the mean for the whole sample), an upgrade to BBB-could be undone by an increase in the risk-free rate of $70 \mathrm{bps}$, or by a rise in the high-yield corporate spread of $50 \mathrm{bps}$.

\section{Ratings}

Credit ratings seldom anticipate changes in the macroeconomic context. On the contrary, there is a growing belief, especially after the experience of the 2007 US mortgage crisis, that rating agencies reflect credit risk only imperfectly. In particular, they tend to respond to markets as much as they do to fundamentals and often lag spreads in their reaction to significant news. If so, ratings will be just a partial proxy for country-specific factors, which would call for a robustness check of our results using a more parsimonious specification.

Our baseline results indicate that ratings exhibit a significant explanatory power for both the long-run level and the short-run variation of emerging spreads. But could ratings be considered as an additional exogenous factor that influences the borrowing cost of emerging economies, independently of whether or not they reveal valuable information? These considerations presume that actual fundamentals may influence both the level of spreads and the way they commove with risk appetite beyond what is summarized by the credit rating.

In order to check this hypothesis, we add to our baseline specification dummies per country-year (when using monthly data) and country-month (when using weekly data) to 
capture the influence of fundamentals identified in the literature as determinants of sovereign risk, such as the country's leverage ratio, the degree of financial and institutional development, or cyclical output fluctuations, which are typically sampled at those frequencies. We include interactions between global factors and the country dummy variables in order to allow elasticities to vary across countries. The coefficients and explanatory power of the original baseline equation remain notably strong, indicating that the influence of global factors is largely independent of country's fundamentals. The explanatory power of both global factors combined jumps to close $80 \%$, at the expense of the country-time dummies. Irrespective of whether the latter truly captures the incidence of domestic factors, the evidence on the explanatory power of global factors appears to be remarkably strong.

While the robustness of the results is reassuring for the two exogenous global factors, it is somewhat intriguing for the case of ratings that, in principle, are conceived as summary indicators of the relevant country-specific factors now included. As noted, this may be due to the fact that, although investors generally recognize the limitations that ratings display in practice, the norms that inform their decisions force them to take credit ratings as a source of variability that is partially exogenous to the policy maker.

The strong empirical association between ratings and spreads has typically been interpreted as evidence that ratings have an impact on the cost of borrowing. In this line, Kaminsky and Schmukler (2002) show that changes in ratings and outlooks are positively correlated with emerging market spreads, particularly so during crisis periods. Then they conclude that ratings are a cause of instability during crises time as they act as a signal that coordinates investors towards a bad equilibrium. Similarly Reinsen and von Maltzan (1998) find evidence of a two-way Granger causality and conclude that negative rating news elicit a significant impact on spreads.

However, more recently, rating agencies have been criticized for overreacting after lagging behind the facts in the context of the Asian and Uruguayan crises. This is the point of Reisen and von Maltzan (1998), Huhne (1998), IMF (1999), among others. It has also been argued that they have been excessively inertial (stabilizing the markets in the run up to a crisis; Mora, 2004) as well as excessively pro-cyclical (contributing to the collapse by downgrading a country by several notches once the crisis is inevitable, Ferri et al., 1999).

We could summarize these ideas suggesting a simpler hypothesis to explain the robustness of the spreads-rating link to the inclusion of country-time dummies: ratings are endogenous to spreads in most cases. To check it, we compare spreads evolution with the date of changes in ratings. We find that downgrades are preceded by increases in spreads and, apart from a mild contemporaneous adjustment (of about 50 bps), exert no substantial impact. However, this does not necessary prove that ratings are endogenous to market reaction (as 
reflected by spreads) since the market may be simply reacting in anticipation of change in ratings. Nevertheless, refining our analysis by considering changes in the credit outlook given by the rating agency does not modify our conclusions.

In sum, the presumption that ratings are a reasonable proxy for fundamental risk is questioned by the data. While their inclusion as control may still be justified, attributing the strong link between ratings and spreads to the incidence of country-specific factors may be misleading, overstating the role of the latter and understating the influence of global factors.

\section{Predictions}

In order to gauge how much of the variation in emerging market spread can be explained by the few exogenous variables identified in our baseline model we simulate individual spread paths. First, we re-estimate the long-run equation using data through the end of 2001, and then we simulate the behavior of spreads that results from variations in the global variables, keeping ratings fixed at their end-2001 levels, for the remaining of the period.

Figure ZZZ.2 compares the actual EMBI spread with the predictions from the long-run equation for four emerging countries ${ }^{2}$. As can be seen, predictions are generally quite good, even for the Latin American countries that underwent severe episodes of capital account reversals during the period. These predictions highlight the explanatory power of the two exogenous variables: despite short-term, transitory swings due to country-specific episodes, spread movements closely reflect these three variables, and eventually converge to levels that are largely explained by them. Brazil is a case in point: the financial turmoil of late 2002associated with the uncertainty surrounding the election and the transition to a new government, which was clearly independent of the evolution of global factors; once over, spreads rapidly converged to their long-run levels.

\footnotetext{
${ }^{2}$ See González-Rozada and Levy Yeyati (2008) for the full results.
} 
Figure ZZZ.2. Spreads: Out-of-sample forecast
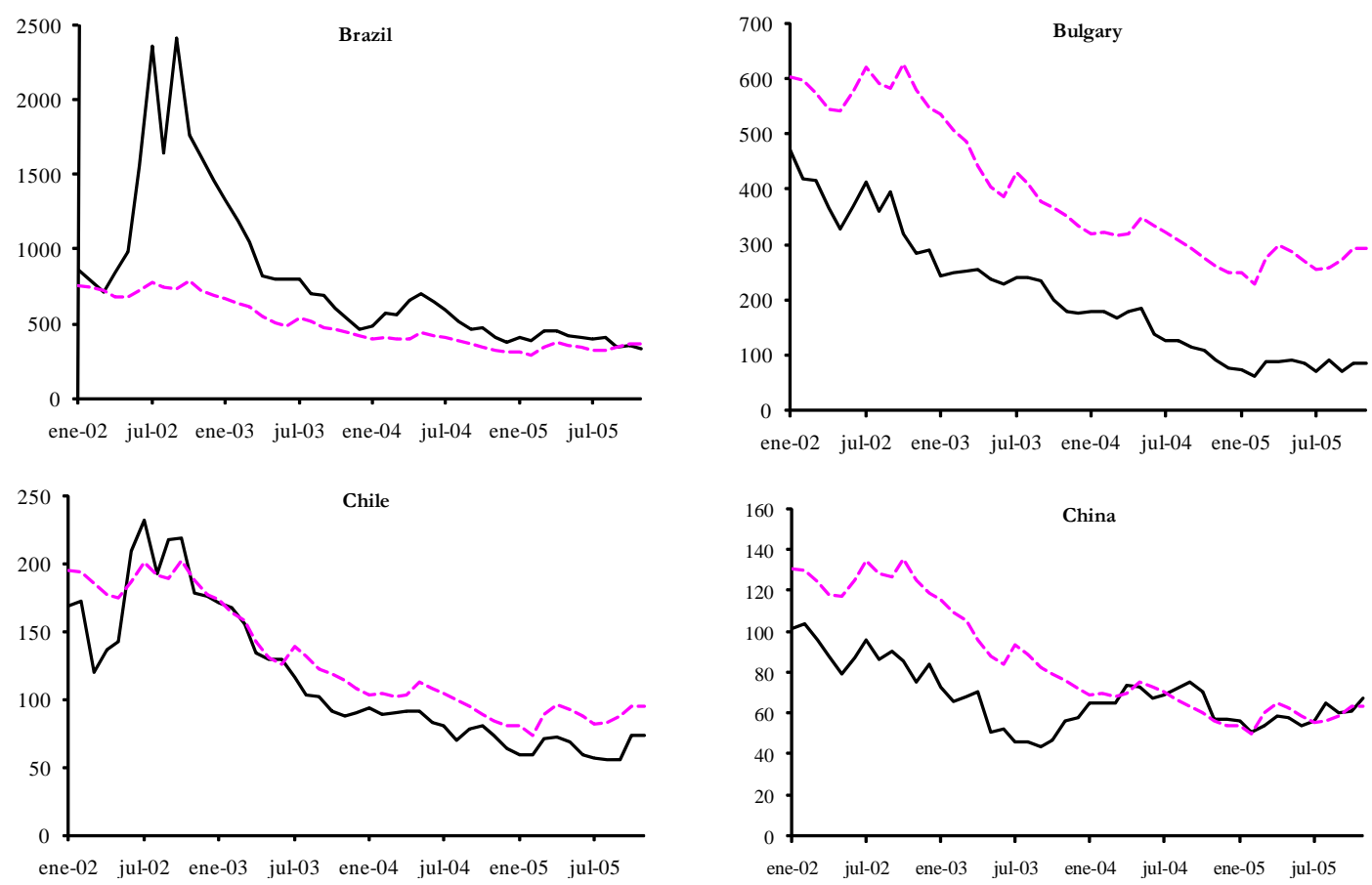

\section{Final Remarks}

This article presented empirical evidence showing that global exogenous factors explain a large part of the substantial volatility exhibitted by emerging market spreads snce the uinception of the asset class in the mid-1990s. We found that emerging market spreads depend negatively on international risk appetite, and positively on international liquidity. These two exogenous factors explain just over $50 \%$ of the long-run time variability of emerging market spreads (14\% of the short-run variability) for the period following the Russian default (2000-2005) and close to $80 \%$ when the elasticities with respect to global factors are allowed to differ across countries. By contrast, ratings appear to be largely endogenous, reflecting changes in spreads rather than anticipating them. Indeed, a closer look reveals that credit ratings or outlook changes lag spread movements, and elicit little if any additional effect on spreads.

These findings contribute to the debate about the nature of emerging market stability, specifically on the degree of exogeneity in the determination of the highly volatile borrowing costs faced by emerging economies - a major source of financial distress in the recent past. In particular, this article suggests that the policy focus should be placed on debt vulnerability to global swings, and on ways to cope with an exogenus deterioration of 
market access, motivating the ongoing debate on precautionary reserve accumulation and global liquidity safety nets.

\section{References}

Calvo, G., Leiderman, L., and Reinhart, C., 1993, "Capital inflows and real exchange rate appreciation in Latin America", IMF Staff Papers, vol. 40(1), (March), pp. 108-151

Ferri, G., Liu, L.-G., and Stiglitz, J.E., 1999, "The pro-cyclical role of rating agencies: evidence from the East Asian Crisis", Economic Notes, vol. 28(3), pp. 335-355

González-Rozada, M and E. Levy Yeyati, 2008, "Global Factors and Emerging Market Spreads," The Economic Journal Vol. 118, Issue 533, pp. 1917-1936.

Huhne, C., 1998, "How the rating agencies blew it on Korea", International Economy, vol.12 (May/June), pp. 46-63

International Monetary Fund, 1999, Emerging Markets in the New International Financial System: Implications of the Asian Crisis, in World Economic and Financial Surveys, International Capital Markets, IMF, Chapter 3

Kaminsky, G., and Schmukler, S., 2002, "Emerging market instability: Do sovereign credit ratings affect country risk and stock returns?", The World Bank Economic Review, vol. 16(2), pp. 171-195

Mora, N., 2004, Sovereign Credit Ratings: Guilty beyond Reasonable Doubt?, Mimeo, Beirut: American University of Beirut

Reinsen, H., and von Maltzan, J., 1998, "Sovereign credit ratings, emerging market risk and financial market risk", HWWA-Institut fur Wirtschaftsforschung, Discussion Paper No. 55 